\title{
The Effect of Active Learning-Based Instructional Program on Improving Motivation and Achievement towards Science among Middle Stage Students with Learning Disabilities in Riyadh
}

\author{
Hanadi Qadan (Corresponding author) \\ Assist. Professor of Special Education, Princess Noura bint Abdul Rahman University \\ Saudi Arabia
}

Received: August 21, 2016 Accepted: September 7, 2016 Published: September 13, 2016 doi:10.5296/ire.v4i2.9934 URL: http://dx.doi.org/10.5296/ire.v4i2.9934

\begin{abstract}
The current study is an attempt to prepare active learning-based instructional program and measure its effectiveness in motivation and achievement towards Science among middle stage students with learning disabilities. The sample consisted of (34) female students, intentionally chosen and distributed into two equal groups, the control group $(n=17)$ and the experimental group $(n=17)$. The author utilized achievement test, motivation scale and the instructional program. The results showed statistically significant differences between the means of scores of the control group and the scores of the experimental group in favor of the experimental group; indicating the effectiveness of active learning-based instructional Science Program in improving achievement and motivation among female students with learning disabilities. The study recommended the need to urge authorities and decision-makers to provide all the instructional supplies that facilitate the application of active learning strategies to students with learning disabilities in the middle stage of public education schools.
\end{abstract}

Keywords: active learning, achievement, motivation, students with learning disabilities, the middle stage

\section{Introduction}

A wide-spread cognitive and technological development featured the current century along with active scientific movement in the development of education strategies for people with 
special needs, including those with learning disabilities. Paying attention to this group of students indicates civilized and cultured nations. To keep pace with this knowledge and technological development, it is needed to teach students with special needs in modern methods of teaching, taking into account their individual differences, potentialities and abilities.

Saudi Arabia is a pioneering country in the application of modern teaching methods for students with special needs, where teaching methods, techniques and strategies focused on individual differences, within less restrictive normal educational framework. A quantum leap has been taken by Saudi Arabia for people with special needs to be included in normal school environment that has become accommodate the largest numbers of these students (Alkhashramy, 2003).

Regulations for Special Education in the Kingdom of Saudi Arabia has confirmed the need for the institutions and programs of special education in normal schools to utilize all methods, techniques and strategies in the educational process and organizing it for people with special needs in commensurate with their abilities and potentials and individual differences among them (Secretariat of Special Education, 2001).

In this connection, the Kingdom of Saudi Arabia was keen on developing specific standards in teachers of learning disabilities, who would provide opportunities for students with learning disabilities in order to become responsible for the initiative and talks with colleagues in meaningful way. The teacher creates the room of sources according to the needs of students with learning disabilities, and he/she uses sources, materials and technical variety, developing and evaluating these sources to support the learning of students with learning disabilities, and looking for a better education strategy that facilitates the transfer of knowledge and skill (National Center for Measurement and Assessment in Higher Education, 2013), this is an indication of the need for teachers of learning disabilities to adopt modern educational strategies to meet the needs of students with learning disabilities and increase their focus and their attention and helps them gain educational experiences in an effective manner.

New trends for learning of those with learning disabilities emerged in the beginning of the twentieth century; these trends called for the need to shift from (Rote Learning), which means receiving the information and memorizing it, to (Active Learning), which means giving the opportunity for the learner to express his/her opinions and ideas freely and exchange them with peers, in the normal classes, and study the relationships between topics, understand concepts and applying these information to the scientific and life situations, until having meaning and purpose in life and career (Abdulwahab, 2005).

Uncertainty and confusion suffered by students with learning disabilities, which could be explained as a result of disintegration of new information in their minds after each learning activity in the traditional method, contributed to the need for active learning. Therefore, studies that have sought to identify the effect of active learning recently emerged to provide an active learning environment among students with learning disabilities. 
In this regard, Hany (2003) and Stewart, Cartier and Passmore (2004) pointed out that the use of active learning strategies have helped in the development of achievement among students with learning disabilities and improving their attitudes towards the educational process.

Bedair (2008) confirmed that active learning raises students' interest and makes their attention lasts for longer periods, due to their preoccupation and interaction with activities, where the active learning aims to teach students with learning disabilities how to learn and how to think, and how actively involved through its strategies, which make learners more effectively and develop their new skills that will help them adapt to new updates, through which they turn from the negative situation (lack of motivation) to energy and activity, speaking, reading, writing, asking questions, practice of activities, thought processes, show of ideas and expressing their views.

Many of the studies used active learning strategies emerged in the teaching and learning process and confirmed its effectiveness, such as that of McCarthy and Anderson (2000), which showed the importance of active learning strategies to increase the academic achievement of students in universities. Carroll and Leander (2001) pointed out that the importance of active learning in increasing the motivation of the elementary fifth grade students to learn social education and in improving their skills thinking to increase their ability to organize and understand the data and information, and promote their social communication skills.

Almahdi (2001) showed the effect of active learning strategies in discussion groups on achievement, conceptual understanding and attitudes towards physics education among first grade secondary students. The results of Hall (2002) showed the impact of the use of active learning strategies on the acquisition of certain biological concepts and the trend towards the positive dependence among first grade secondary students. Alzoubi (2007) also showed the impact of active learning program in accordance with the cognitive social theory on the degree of social competence and academic achievement among students of elementary third grade.

Tandogan and Orhan (2007) indicated that problem solution based on active learning strategies contributes to improving the academic achievement and acquiring scientific concepts among seventh grade students in science. Scheyvens et al. (2008) confirmed that the active learning increases the motivation of students to learn and work to form positive trends, also it increases the students' understanding of school subjects and promotes self-learning and their confidence in their ability to learn, the study also resulted that active learning improves academic achievement. Ravi et al. (2009) indicated the importance of active learning for students to acquire the following skills: resource management, organization, personal skills, interpersonal, and communication skills. The study of Alzaidi (2010) showed the impact of active learning on the development of creative thinking and academic achievement for the subject of science among third-grade middle students.

Many studies, in the field of special education, illustrated the effectiveness of active learning applications for students with special needs, where Abdul karim (2009) showed the effect of a program based on active learning on social studies in the development of some of the life 
skills and achievement among a sample of female students with mild intellectual disabilities. Alenzi (2010) illustrated the effectiveness of active learning on improving achievement in the Arabic language and to improve motivation toward learning among gifted students in the ninth grade.

Through the pieces of literature and views mentioned earlier on the importance of the application of active learning strategies to normal students and those with special needs, as recommended by Ravi et al. (2009) the need to the use of active learning with students of different grade levels, and Albataynh et al. (2009) also indicated the importance of motivation in the development of the learning process for students with learning disabilities and achieving their desire to seek and engage in educational tasks, and what confirmed by Alrawsan (2006) that the achievement motivation have a direct role in the performance of students with learning disabilities and have an impact on academic achievement, so the current study conducted by the author to investigate the effectiveness of an educational science program based on active learning in improving the achievement and motivation among middle stage students with learning disabilities in Riyadh.

\section{Statement of the Problem}

The modern trends of special education emerged due to American Act 94/142, issued in 1975 in the United States, an act known as "Individuals with Disabilities Education ACT, IDEA", which compel educational institutions to provide education for students with special needs including those with learning disabilities, which is commensurate with their abilities for the provision of appropriate educational and support services needed by the student with special needs (Alwabili, 2000).

Owing to the broad development in the field of special education, Saudi Arabia was keen on applying the American act, approved by the educational institutions for those with special needs, those institutions are committed to provide all of the teaching methods and strategies for people with special needs in order to overcome the disabilities and be included in community to be productive individuals. The General Secretariat for Special Education issued regulations to organize work in institutions and programs for special education assuring the importance of using modern teaching strategies in the education of those with special needs (Secretariat for Special Education, 2001).

Out of our concern for students with learning disabilities, giving them an active role in classroom situations, as confirmed by many studies conducted in this area and showed the effectiveness of active learning in the education and training of students with learning disabilities such as Hany (2003) and Stewart, et al (2004); but the author of the current study, working as supervisor of female students in the field of learning disabilities at Princess Noura bint Abdul Rahman University, noted that most female teachers of students with learning disabilities focus on using traditional teaching methods, techniques and strategies, which does not take into account the individual differences among students with and without learning disabilities, and these strategies are not in line with their abilities and needs.

Therefore, the current study sought to answer the following key question: What is the 
effectiveness of active learning-based instructional science program in improving motivation and achievement among middle stage students with learning disabilities? Resulting in the following two questions:

1) Are there any statistically significant differences at the level of $(\mathrm{a}=0.05)$ between the control group and the experimental group on the post achievement test?

2) Are there any statistically significant differences at the level of $(a=0.05)$ between the control group and the experimental group on the post motivation scale?

\section{Significance}

The educational literature and the studies that handled the current study variables enriches the Arab library, and contribute to the increase of human knowledge about the importance and impact of active learning in improving motivation and academic achievement among female students with learning disabilities, thus the current study can be a pillar for researchers and scholars.

The importance of the current study also lies in conveying the effectiveness of active learning-based instructional science program in improving motivation and achievement among middle stage students with learning disabilities; thus contributing to attracting schools and centers specialized in education and training for people with learning disabilities to apply this program, where it simplifies the educational process, time management and organizing the scientific content of subjects, and it also makes the classroom an effective place providing female students with learning disabilities with experiences profiting them in the scientific and practical life.

Moreover, the current study also gives a vision for the officials of the educational process and decision-makers about the importance of active learning; which contributes to drawing their attention to the development of plans, programs and methods that help meet the educational needs among students with learning disabilities in the Kingdom of Saudi Arabia and the Arab world.

\section{Methodology and Procedures}

This section of study deals with a description of the study methodology and its sampling, and the instruments used for data collection, and methods of verifying their validity and reliability, in addition to procedures for the application of the study.

\subsection{Method}

The current study adopted a quasi-experimental approach, and Nonequivalent Control Group Design was utilized, which is based on the causal relationship between two variables, one independent and the other is the dependent variable; the control group and the experimental group used in the present study to measure the effectiveness of the independent variable of active learning strategies, where the control group taught traditionally, while the experimental one taught according to the strategies of active learning along with the pre-and-post academic achievement test and motivation scale toward learning. 


\subsection{Participants}

The sample consisted of (34) $1^{\text {st }}$ and $2^{\text {nd }}$ grade middle stage female students with learning disabilities and were diagnosed according to the criteria approved by the Ministry of Education in Saudi Arabia, they were intentionally chosen from one of the schools in the city of Riyadh. The participants distributed to two equal groups, control group $(n=17)$, and the experimental group $(\mathrm{n}=17)$ who studied using active learning strategies.

\subsection{Instrument}

\section{First: Achievement Test}

The author of the current study prepared achievement test to measure the level of female students with learning disabilities in pre and post academic achievement test in science, including (25) paragraphs of multiple choice.

\section{Validity \& reliability}

The test paragraphs evaluated by a number of referees and reviewers of the College of Education members at the University of Princess Noura and King Saud University, they were also reviewed by the educational supervisors and female teachers teaching science to middle stage students. The referees and reviewers were asked to express their opinion on the appropriateness of the paragraphs of the test for the objectives of the study for the middle stage students with learning disabilities, the referees made some remarks, and the necessary modifications made in line with their recommendations.

The final draft of the achievement test has been applied to pilot sample of (10) female students; and through using Kuder-Richardson Formula 20 (KR-20), the total test reliability was $(0.81)$; it is a proper value for test reliability and appropriateness for the purposes of the study.

\section{Secondly: Motivation Scale}

Motivation scale was developed in this study after reviewing the educational literature on motivation in order to identify its concept and aspects (Ghabary, 2008 \& Zaghoul, 2011), as well as taking into account the scales used in the pieces of literature review that addressed motivation among students as Alsafy (2000) and Alaboyny (2008). The final draft of the scale consisted of (29) paragraphs after verifying its validity and reliability. The participants respond by checking a mark $(\sqrt{ })$ in front of each paragraph of the domains on five-point Likert type (always, often, sometimes, rarely, and never) for the grades $(5,4,3,2$, and 1 ) respectively for the five alternatives.

\section{Validity}

Ten referees and reviewers in the field of special education, measurement and assessment in Saudi Universities verified the validity of the first draft of motivation scale, where they checked the appropriateness of the paragraphs of the scale as a whole, and to make sure the language and phrasing to achieve the objectives of the study. In light of the views and 
suggestions of the evaluators, the required modifications were made by agreement rate $(80 \%)$.

\section{Reliability}

Test and retest method verified reliability of the motivation scale to a pilot sample of (20) female students with learning disabilities, Pearson correlation coefficient was calculated between their scores, with time interval, and the total reliability coefficient in this way was (0.85). Reliability coefficient also calculated by internal consistency through (Cronbach's Alpha), thus the reliability coefficient for the total scale was $(0.91)$, which refers to the appropriateness of the scale to achieve the objectives of the study.

\section{Thirdly: The Instructional Program}

\section{Description:}

The active learning is considered an educational philosophy based on positive educated in the classroom, this philosophy includes a number of educational practices and teaching procedures that lead to the activation of the learner's role, so learning done through experimentation, work and research, and then the learner got information first hand, as well as the acquisition of skills and the formation of values and attitudes; thus, the learner transforms from rote learning and indoctrination to the development of thinking skills and the ability of problem-solving, teamwork and cooperative learning skills

\section{Preparation steps:}

The following steps adopted for the preparation of the instructional program:

1) Access to educational literature to identify what is meant by active learning strategy, in terms of concept, elements, active learning-based teaching, and how to apply it educationally, especially in science.

2) Access to the pieces of literature review that have designed instructional strategies based on the active learning in teaching at various educational subjects, especially science, in order to determine the teaching goals, and how to follow the instructional steps.

3) Choosing the topics that have been taught in the subject of science: power and electrical circuit, voltage rate, electrical resistance, Ohm's law, connecting resistors, driving power, and the equivalent circuit.

4) Determining of active learning strategies that are used in teaching: brainstorming, cooperative learning, using the Think-Pair-Share Technique, five-person learning cycle strategy.

5) The educational content of the program is designed through Power Point application.

6) Setting a schedule for achieving the goals, and the content of the instructional program based on the science curriculum at the middle stage. The instructional program applied in two weeks rated one session a day. 


\section{Macrothink}

7) The program is designed in collaboration with supervisors and teachers of Science in Riyadh.

8) A group of referees verified the validity of program content, where they were asked to give their feedback about the program and its content in science for middle stage students, the steps used in teaching, and its appropriateness to the academic level of the participants.

9) It was agreed with the female teacher in charge of the experimental group that the teaching process is monitored by the author of the study in order to verify that this program is well applied by the teacher in the classroom.

\section{Components:}

1) Introduction to the subject of training: preliminary introduction for the learner about the training process.

2) Content type: texts, graphics and images/animations.

3) Pause: the learner can pause during the learning process, closing the program then returns to the program for achieving the learning process.

4) Response evaluation: the learner can access the result of what he learned through the feedback stored in the program.

\section{Application}

The current study was conducted in the second semester for the academic year 2015/2016, the participants distributed randomly into two equal groups, the control group and the experimental group, the program applied by the female teacher of science to the experimental group. The pre-measuring conducted to verify the equivalence between the two groups. Then, the means and standard deviations calculated for the scores of the pre achievement test, and the pre motivation scale, as shown in Table (1):

Table (1). Means and standard deviations, and the results of t-test on the pretest for achievement and motivation

\begin{tabular}{|c|c|c|c|c|c|c|}
\hline Instrument & Group & No. & Mean & $\begin{array}{c}\text { Standard } \\
\text { deviation }\end{array}$ & T-value & $\begin{array}{c}\text { Significance } \\
\text { level }\end{array}$ \\
\hline Achievement test & Control & 17 & 8.38 & 2.95 & 0.87 & $* 0.38$ \\
\cline { 2 - 7 } & Experimental & 17 & 7.76 & 2.88 & & \\
\hline Motivation scale & Control & 17 & 2.39 & 0.42 & 0.79 & $* 0.23$ \\
\cline { 2 - 5 } & Experimental & 17 & 2.30 & 0.36 & & \\
\hline
\end{tabular}

* Not statistically significant at the significance level $(\mathrm{a}=0.05)$. 
Table (1) showed no statistically significant differences at the significance level $(a=0.05)$ between the control group and experimental group on the pretest of achievement and scale of motivation; indicating the equivalence of the two groups.

The experimental group trained on the educational content of the program through active learning strategies, one period a day for two consecutive weeks in the source room at the middle school under the direct supervision of the author, while the control group trained by the teacher of science at the school in accordance with the normal traditional method in the classroom.

At the end of the training, post science achievement test and post motivation scale applied for evaluating the effectiveness of active learning-based instructional program.

\section{Results}

Results of the first question: Are there any statistically significant differences at the level of $(a=0.05)$ between the control group and the experimental group on the post achievement test? To answer this question, the means and standard deviations calculated between the scores of the control group and the experimental group on the post achievement test, and ( $\mathrm{T}$. test) conducted to identify the significance of differences between the means and standard deviations, as illustrated in Table (2).

Table (2). Means and standard deviations, and the results of t-test for the post achievement test

\begin{tabular}{|c|c|c|c|c|c|}
\hline Group & No & Mean & St. D & T-value & Sig. level \\
\hline Control & 17 & 12.65 & 5.77 & \multirow{2}{*}{3.61} & $* 0.001$ \\
\cline { 1 - 4 } Experimental & 17 & 17.35 & 4.97 & & \\
\hline
\end{tabular}

* Statistically significant at the significance level $(\mathrm{a}=0.05)$.

Table (2) showed statistically significant differences between the means of the control group who studied in the traditional way and the means of the experimental group that studied using the instructional program on the post achievement test, where the arithmetic mean of the control group was (12.65), while the mean of the experimental group was (17.35), the value of "T" was (3.61) and statistically significant at (0.001), where the differences were in favor of the experimental group; indicating the effectiveness of the instructional program based on active learning to improve achievement among female students with learning disabilities (the participants of the experimental group).

Results of the second question: Are there any statistically significant differences at the level of $(a=0.05)$ between the control group and the experimental group on the post motivation scale? To answer this question, the means and standard deviations calculated between the scores of the control group and the experimental group on the post motivation scale, (T. test) 
conducted to identify the significance of differences between the means and standard deviations, as illustrated in Table (3).

Table (3). Means, standard deviations, and t-test for the post motivation scale

\begin{tabular}{|c|c|c|c|c|c|}
\hline Group & No & Mean & St. D & T-value & Sig. level \\
\hline Control & 17 & 2.70 & 0.36 & \multirow{2}{*}{3.313} & $* 0.00$ \\
\cline { 1 - 4 } Experimental & 17 & 3.34 & 0.38 & & \\
\hline
\end{tabular}

* Statistically significant at the significance level $(a=0.05)$.

Table (3) showed statistically significant differences between the means of the control group the means of the experimental group, where the arithmetic mean of the control group was (2.70), while the mean of the experimental group was (3.34). The value of " $T$ " was (3.313) and statistically significant at (0.00), the differences were in favor of the experimental group; indicating the effectiveness of the instructional program based on active learning in improving motivation among female students with learning disabilities (the participants of the experimental group).

\section{Discussion}

The results of the current study showed statistically significant differences in the post achievement test, where the differences were in favor of the experimental group members, who have been trained on the active learning-based instructional program compared to members of the control group who have been traditionally trained, which means that this program was effective in the development of achievement among members of the experimental group, and has an impact on improving the ability of the experimental members to identify the content displayed at the program. The result can attributed to what referred to by Bedair (2008) that active learning helps gain educational experiences in an effective manner, form integrated personality for students with learning disabilities, and develop thinking skills

Therefore, active learning addresses many of these skills in different situations, so it helps improve learning the scientific content. The active learning strategies make the learner active during the acquisition of skills in various learning situations that are full of excitement, competition and consolidation, as the educational strategy adopted taking into account the individual differences of the learners, and enables them to learn owing to their abilities.

The current results are consistent with the results of pieces of literature review, for example, Hany (2003) and the study of Stewart, et al, (2004), which showed the effectiveness of using active learning strategies in the development of achievement among students with learning disabilities, the study of Alzoubi (2007) showed that the program of active learning has an impact on academic achievement among students of primary third grade, Tandogan and Orhan (2007) indicated that active learning contribute to improving the academic achievement among seventh grade students of science, as well as Abdul Karim (2009), which 
showed that active learning affected the development of achievement among students with mild intellectual disabilities, and the study of Alenzi (2010), which showed that the results of active learning contribute to improving achievement among female gifted students.

The results also showed statistically significant differences in the posttest of motivation scale, where differences were in favor of the experimental group members, who have been trained on the active learning-based instructional program compared to members of the control group, who studied in the traditional way, which means that the program was effective in developing the motivating of the experimental group.

The author of the current study believes that the environment provided by active learning program during the teaching and learning process, in terms of communication and interaction between the learners, generates positive attitudes they have towards the instructional content displayed at the program from one hand, and toward the subjects they study from the other hand, which increases the motivation to learn, and the attitudes of female students with learning disabilities about the subject displayed (Science) changed for the positive, which explains improving the motivation. The strategies used in active learning contributed to raising the level of classroom participation among the female students with learning disabilities, and interacting with the teacher and with their peer female students through the expression of their ideas and opinions, thus helping increase the enthusiasm and desire to participate in answering the questions posed during the teaching process.

The results of the current study are consistent with the results of Scheyvens, et al. (2008), which showed that active learning raises students' motivation to learn, as well as Alenzi (2010), which showed that active learning contributes to improving motivation toward learning among outstanding students.

\section{Recommendations}

In light of the results of the study the author made the following recommendations:

1. Further studies should be conducted to measure the impact of using active learning on developing the skill of problem-solving, creative thinking and critical thinking among female students with learning disabilities.

2. Urging authorities and decision-makers to provide all the supplies that facilitate the application of active learning strategies for middle stage students with learning disabilities in public schools.

3. The need to educate teachers of Science at the intermediate level about the importance of adopting strategies of active learning in the educational process.

\section{References}

Abdul Karim, G. (2009). The effect of active learning-based program in social studies upon the development of some of the life skills and achievement among students with intellectual disabilities who are able to learn. Unpublished MA Thesis. Egypt: Qena, Faculty of Education. 
Abdulwahab, F. (2005). The effectiveness of the use of certain active learning strategies in the achievement of science and the development of lifelong learning skills and scientific interests among the fifth-grade elementary students. Journal of Scientific Education, (2), 127-185.

Alaboyny, J. (2008). Causal model of the relationship between parental inclusion, locus of control and motivation of academic achievement on the one hand and creative thinking on the other hand among the tenth grade elementary students in Jordan. Unpublished PhD thesis. Jordan: Yarmouk University.

Albatayneh, et al. (2009). Learning Disabilities: Theory and Practice. Jordan: Amman, Dar Almaseera.

Alenzi, M. (2010). The application of active learning using strategies of chattering groups and questions to excellent female ninth grade students and its impact on Arabic language achievement and motivation toward learning, Kuwait. Unpublished Master Thesis. Jordan: University of the Middle East.

Alkhashramy, S. (2003). The development of special education in the Kingdom of Saudi Arabia: Paper presented at the Saudi cultural week in Jordan. Jordan: Ammaan.

Almahdi, M. (2001). The impact of the application of active learning strategies for discussion groups on achievement, conceptual understanding and attitudes towards physics among the first grade secondary students. Scientific journal of Education, 4(2), 107-147.

Alrawsan, F. (2006). Introduction to Special Education. Amman: Dar Alfikr for publication and distribution.

Alsafy, A. (2000). Attribution of success and failure and its relationship to motivation for achievement among excellent and backward university students in Abha. Journal of Umm Al-Qura University for Educational, Social and Human Sciences, 12(2), 81-106.

Alwabili, A. (2000). requirements Using of educational plan and its importance in the field of education and training of intellectually retarded students in Saudi Arabia. Mission of Education and Psychology, (12), 1-47.

Alzaidi, F. (2010). The effect of active learning in the development of innovative thinking and academic achievement in science among the third-grade-middle stage students in public schools of Makka, unpublished Master Thesis. Saudi Arabia: University of Umm Al-Qura.

Alzoubi, A. (2007). The impact of active learning program in accordance with the social cognitive theory on the degree of social competence and academic achievement of elementary third grade students, unpublished Ph. D. Jordan: Amman, University of Jordan.

Bedair, C. (2008). Active learning. Jordan: Amman, Dar Almaseera.

Carroll, L., \& Leander, S. (2001). Improve Motivation through the Use of Active Learning Strategies. Unpublished Master Dissertation. Saint Xavier University. 
Secretariat for Special Education. (2001). Regulatory rules for institutes and programs Special Education for the Ministry of Education. Riyadh: Press of Secretariat for Special Education.

Ghabary, T. (2008). Motivation. Amman: Dar Almaseera for printing, publishing and distribution.

Hall, S., Watiz, I., Bordeur, D., \& Nas, R. (2002). Adoptional of Active Learning in alectrure-Based Engineering Class. ASEE IEEE Frontiers in Conference. 6-9 November, Boston. MA.

Haney, J. J. (2003). Constructivist beliefs about the science classroom learning environment: Perspectives from teachers administrators, parents, community members \& students. School Science and Mathematics, 103(8), 366-378.

McCarthy, J., \& Anderson, L. (2000). Active Learning Techniques versus Traditional Teaching Styles: Two Experiments from History and Political Science. Innovative Higher Education, 24(4), 279-294.

Ravi shankar, A., \& others. (2009). Comparing the impact of active learning in a secondary school with research-led teaching in a medical school. Cambridge Journals, 68, 823-830.

Scheyvens, R., Griffin, A., Jocoy, C., Liu, Y., \& Bradford. (2008). Experimenting with Active Learning in Geography: Dispelling the Myths That Perpetuate Resistance. Journal of Geography in Higher Education, 32(1), 51-69.

Stewart, J., Cartier, J., \& Passmore, C. M. (2004). Developing understanding though based inquiry. American Assosiation for the Advancment of Science, Washington.

Tandogan, R., \& Orhan, A. (2007).The Effects of Problem-Based Active Learning in Science Education on Students' Academic Achievement, Attitude and Concept Learning. Journal of Mathematics, Science \& Technology Education, 3(1), 71-81.

The National Center for Measurement and Assessment in Higher Education. (2013). Teachers' standards of learning disabilities. Riyadh: King Abdullah Project for the Development of Education.

Zaghoul, I. (2011). Principles of Educational Psychology. Amman: Dar Almaseera for publishing, distribution and printing.

\section{Copyright Disclaimer}

Copyright reserved by the authors.

This article is an open-access article distributed under the terms and conditions of the Creative Commons Attribution license (http://creativecommons.org/licenses/by/3.0/). 